\title{
UMA ABORDAGEM FILOSÓFICA DO CAPITALISMO É POSSÍVEL? LIMITES E POSSIBILIDADES DE RENOVAÇÃO DA FILOSOFIA SOCIAL CONTEMPORÂNEA*
}

\author{
Leonardo da Hora Pereira** \\ leonardojorgehp@gmail.com
}

RESUMO Neste artigo, procuraremos contribuir, dentro dos limites de um trabalho dessa natureza, para uma nova orientação para a filosofia social contemporânea. Com efeito, num primeiro momento mostraremos que a filosofia social recente tem se notabilizado pela análise de experiências negativas, com um acento no processo de formação da subjetividade, assim como pelo foco no diagnóstico de patologias sociais relacionadas aos padrões subjetivos de autorrealização pessoal. Num segundo momento, salientaremos que o problema é que, nesse quadro, o próprio social pode eventualmente aparecer como algo tão-somente negativo, ameaçador, deficitário e gerador de patologias. Ora, acreditamos que o desafio de captar igualmente a causa das patologias, os poderes e a perspectiva do dominante, e não somente os efeitos deletérios por eles gerados e a perspectiva dos dominados, pode ser melhor enfrentado por meio da temática do capitalismo como fenômeno social. É por isso que iremos esboçar, em linhas gerais, num terceiro momento, algumas diretrizes básicas - uma abordagem praxeológica e "normativa" - para que a filosofia social simultaneamente mantenha suas conquistas fundamentais e avance no sentido de dar conta diretamente do social capitalista como causa de patologias.

Palavras-chave Filosofia social, capitalismo, teoria crítica. 
ABSTRACT In this paper, we will seek to contribute, within the limits of a work of this nature, to a new orientation for contemporary social philosophy. In fact, in a first moment we will show that the recent social philosophy has been notable for the analysis of negative experiences, with an emphasis on the process of subjectivity formation, as well as for the focus on the diagnosis of social pathologies related to the subjective patterns of personal self-achievement. In a second moment, we will point out that the problem is that, in this context, the social itself may eventually appear as something exclusively negative, threatening, deficient and generating pathologies. However, we believe that the challenge of capturing equally the cause of the pathologies, powers and the perspective of the dominant, and not only the deleterious effects generated by them and the perspective of the dominated, can be better dealt with through the theme of capitalism as a social phenomenon. That is why we will outline, in a third way, some basic guidelines - a praxeological and normative approach-so that social philosophy may simultaneously maintain its fundamental conquests and advances in order to directly account for the capitalist social as cause of pathologies.

Keywords Social philosophy, capitalism, critical theory.

\section{Introdução}

A pressão da crise contemporânea do capitalismo é tamanha que a análise e a crítica desse fenômeno social voltou à ordem do dia em alguns setores do campo acadêmico da Filosofia e das Ciências Sociais. Assim, na vertente da teoria social crítica, assistimos ao surgimento de vários tipos de discursos críticos e denúncias sobre os efeitos de dominação, exploração e alienação causados pela atual fase do capitalismo. Livros como aquele publicado em 1999 por Luc Boltanski e Eve Chiapello, "O novo espírito do capitalismo", assim como "Império" de Antonio Negri e Michael Hardt, publicado em 2000, não só restauraram a legitimidade do uso da palavra "capitalismo", mas também reabriram o campo teórico de análise crítica do capitalismo. Desde então, a abundância da literatura militante relacionada com o movimento altermundialista, a fertilidade de renovadas abordagens marxistas tanto em Filosofia como em Ciências Sociais e o renascimento de correntes críticas e heterodoxas em Economia têm transformado a paisagem teórica.

No campo filosófico, o evento mais importante nesse sentido foi, provavelmente, o renascimento da filosofia social. Neste artigo, procuraremos 
contribuir, dentro dos limites de um trabalho dessa natureza, para uma nova orientação para a filosofia social contemporânea. Com efeito, num primeiro momento, mostraremos que a filosofia social recente tem se notabilizado pela análise de experiências negativas, com um acento no processo de formação da subjetividade, assim como pelo foco no diagnóstico de patologias sociais relacionadas aos padrões subjetivos de autorrealização pessoal. Num segundo momento, salientaremos que o problema é que, nesse quadro, o próprio social pode eventualmente aparecer como algo tão-somente negativo, ameaçador, deficitário e gerador de patologias. Ora, acreditamos que o desafio de captar igualmente a causa das patologias, os poderes e a perspectiva do dominante, e não somente os efeitos deletérios por eles gerados e da perspectiva dos dominados, pode ser melhor enfrentado por meio da temática do capitalismo como fenômeno social. É por isso que iremos esboçar, em linhas gerais, num terceiro momento, algumas diretrizes básicas - uma abordagem praxeológica e normativa - para que a filosofia social simultaneamente mantenha suas conquistas fundamentais e avance no sentido de dar conta diretamente do social capitalista como causa de patologias. Bem entendido, um maior aprofundamento dessa proposta se dará eventualmente em outra ocasião. $\mathrm{O}$ foco do artigo é o momento crítico-analítico a respeito da filosofia social contemporânea, visando a preparar o terreno para a superação das dificuldades que serão assinaladas ao longo desse texto.

\section{O que é a filosofia social?}

Em que consiste esse gênero filosófico conhecido como filosofia social? Em primeiro lugar, podemos distingui-lo de outros tipos de filosofia prática, e especialmente da filosofia política, uma vez que a filosofia social é particularmente atenta à análise do "social" e, portanto, aos trabalhos das Ciências Sociais, os quais não são para ela meras ocasiões de exemplificação, mas um verdadeiro ponto de partida. Em outras palavras, a interdisciplinaridade e o diálogo com as ciências sociais são constitutivas e certamente não um simples acessório para a filosofia social. Ela também difere de outras teorias sociais, uma vez que defende um tipo de abordagem especificamente filosófica do social: uma abordagem em que o social é considerado de forma privilegiada sob o ângulo daquilo que ele tem de propriamente normativo. Se inspirando notadamente no conceito hegeliano de eticidade (Sittlichkeit), boa parte da filosofia social contemporânea enfatiza o fato de que os atores investem o social de expectativas normativas das quais eles esperam a realização. Em outras palavras, naquilo que diz respeito ao social, estamos sempre lidando com uma mistura de normas e estruturas, isto é, tanto com estruturas que incorporam e realizam normas, como 
com normas e expectativas normativas que tendem a se realizar em estruturas sociais (Fischbach, 2013, p. 12). É precisamente por isso que não se trata de uma teoria da sociedade, mas de uma filosofia do social, isto é, de uma teoria que é capaz de dar conta do teor e do alcance normativo das relações sociais. Essa filosofia "tem os meios para compreender a dimensão normativa imanente ao social; uma dimensão normativa que não expressa nada além do horizonte de expectativa dos próprios atores, isto é, as expectativas de que, nas relações sociais, eles tenham, o máximo possível, chances de possuir uma boa vida" (Fischbach, 2013, p. 18). ${ }^{1}$

De acordo com essa concepção, o social e moral não podem ser pensados separadamente: é o social que funda a moral, não só em seu conteúdo (o social determina o que consideramos como moral), mas também na sua forma, quer dizer, como algo que simultaneamente desejamos e que se impõe a nós como obrigação ou dever. É uma mistura de realidade e de idealidade, de funcionamento social e de aspiração moral, de ser e de vontade. A compreensão filosófica do social evitaria assim uma análise puramente descritiva ou positivista do social: "Por social ou sociedade, não se entende somente algo que é, somente algo do qual se constata a existência, mas algo de almejado e de desejável, algo a se querer e a se fazer; não apenas alguma coisa que vemos, mas que queremos; não apenas algo a que nos submetemos, mas algo que escolhemos" (Fischbach, 2013, p. 20).

A partir dessa perspectiva, se torna claro que pertence igualmente à filosofia social uma função crítica essencial. Em relação a isso, poderíamos nos colocar a seguinte questão: sobre o que, em nome de que e em vista de que podemos criticar tal instituição, tal forma de vida, tal forma de organização social? A filosofia social contemporânea, que se estabelece fundamentalmente a partir da obra de Axel Honneth (2003; 2008; 2012; 2013), responde que

é exatamente em função do que existe de desejável e de almejado no social que uma crítica do social, tal como este existe, torna-se possível, com a condição de precisar que o social desejável não se funda, e não pode se fundar, sobre outra coisa que não seja o social existente; donde a necessidade de conhecer este último para determinar o primeiro (Fischbach, 2013, p. 20).

O objetivo é assim extrair as características desejáveis das formas de vida comunitárias que realmente existem, usá-las para criticar características indesejáveis e sugerir melhorias. Esses traços desejáveis não podem, obviamente, 
ser eles mesmos escolhidos arbitrariamente. Eles são os traços característicos do social tal como ele é, tal como ele realmente existe no tecido social.

Nesse caso, qual seria a melhor maneira de acessar ou de "ler" a normatividade imanente ao social, que fornece também os critérios de crítica social? As respostas podem variar aqui. Como explica Emmanuel Renault (2013, p. 268), as normas da crítica podem ser buscadas na explicação de um conjunto de expectativas normativas fundamentais que deveriam ser imanentes à vida social, seja à maneira de uma gramática profunda das interações (como as pressuposições comunicativas da interação em Jürgen Habermas, ou as expectativas de reconhecimento em Axel Honneth), seja à maneira de um conjunto de promessas inscritas nas estruturas fundamentais de uma época histórica (como aquelas da modernidade em Habermas e Honneth). Também é possível falar de imanência normativa à uma instituição (o Estado, o mercado) ou a práticas sociais.

A filosofia social francesa contemporânea se notabilizou, ainda, pelo aprofundamento de uma abordagem particular, já presente em Honneth. Se nos referirmos à apresentação da filosofia social por Franck Fischbach, por exemplo, constatamos que ele a define em "Manifeste pour une philosophie sociale» como uma reflexão crítica sobre a sociedade que

tem seu ponto de partida nas formas e experiências de vida que são vividas pelos
próprios agentes como não realizadas, alienadas, degradadas e mutiladas, e ela procura
identificar no contexto social e histórico dessas formas de vida as condições que
as tornam formas mal-sucedidas, ao ponto, muitas vezes, de se tornar intoleráveis
desencadear o protesto ou a revolta (Fischbach, 2009a, p. 15).

Vemos assim colocado no centro da análise o problema da experiência negativa que os indivíduos vivenciam em relação a entidades e dinâmicas sociais objetivas. Como bem resume Fischbach, trata-se de partir da pergunta "o que é uma vida humana alienada ou mutilada?", na medida em que essa "implica um tipo determinado de questionamento filosófico e uma forma singular de investigação que diz respeito ao que chamaremos aqui de filosofia social" (Fischbach, 2009a, p. 15).

Stéphane Haber vê na centralidade da experiência individual negativa (à qual se referem conceitos críticos como alienação, exclusão, sofrimento ou exploração), como quadro de leitura privilegiado do social, a principal contribuição da filosofia social francesa:

Mais precisamente, a contribuição da recente filosofia social de língua francesa parece ter sido a de mostrar como a experiência individual forma o centro de gravidade da investigação. Pois, bem compreendidos, conceitos tais como alienação, exclusão, 
dominação, além de fazerem referência sem hesitação a uma espécie de substrato antropológico universal, também supõem que o social é, pelo menos numa primeira abordagem, presente e corretamente legivel segundo a maneira que o individuo o experimenta, especialmente nas experiências negativas em que seu ambiente social lhe aparece como um obstáculo, como uma fonte de decepção, embaraço, frustração e sofrimento. Estamos bem longe da hostilidade objetivista e estruturalista ao consciente $e$ ao vivido. Este distanciamento nos traria mesmo de volta às paragens de uma espécie de velho reflexo fenomenológico, aquele que leva a insistir sobre o fato que, se os "fatos sociais" só poderiam ser considerados "como coisas", como Durkheim queria, é porque eles são efetivamente estabelecidos por pessoas em circunstâncias ou contextos interativos determinados e, desta forma, afetam os indivíduos de volta (Haber, 2012, p. 139, grifo nosso).

A novidade trazida pela filosofia social francesa é então que esta dimensão (o que a sociedade faz aos indivíduos) é agora ressaltada. O ponto de vista da crítica é reconstruído na medida em que a crítica é interpretada como uma prática social que surge das experiências negativas nas quais as situações sociais se apresentam como não conformes a expectativas normativas fundamentais. A crítica aparece "como uma reação cognitiva à experiência negativa e como um processo reflexivo, vinculado a uma tentativa de resolução prática de uma situação problemática" (Renault, 2013, p. 268). A experiência singular que os indivíduos fazem e suas reações práticas, afetivas e cognitivas são, portanto, levadas a sério, o que oferece à filosofia social um conhecimento das tensões e das contradições que estruturam a experiência social. O conceito de patologia social ${ }^{2}$ torna-se central. Assim a filosofia social se interessa menos pelos critérios de legitimidade do poder político (como o faria a filosofia política clássica) e mais pelos limites que as evoluções problemáticas do tempo presente impõem ao ser humano em sua busca de realização de si. A dimensão propriamente social da vida (isto é, as condições sociais efetivas dos atores sociais) adquire, dessa forma, uma primazia notável.

Nessa perspectiva, a filosofia social, especialmente a de origem francesa, tem contribuído grandemente para a análise e a crítica das patologias sociais do capitalismo contemporâneo, particularmente na dimensão do trabalho. Nesse contexto, temos assistido ao retorno com força do uso de conceitos críticos como os de alienação (Jaeggi, 2005; Haber, 2007; Fischbach, 2009b), de reificação (Honneth, 2005) e de sofrimento (Dejours, 2014; Renault, 2008).

2 Honneth (2008, p. 35) descreve as patologias sociais como as deficiências sociais dentro de uma sociedade que não resultam simplesmente de uma violação dos princípios comumente aceitos de justiça, mas de violações às condições sociais de autorrealização individual. Isso quer dizer que as patologias sociais são relações ou desenvolvimentos sociais que afetam as condições de autorrealização de si (ibidem, p. 179). 
Por exemplo, Emmanuel Renault mostra que, até hoje, o discurso político com pretensões emancipatórias permanece marcado por critérios de exigência a favor de democracia, de justiça e de vida boa. No entanto, a decomposição do dispositivo institucional vinculado à fase fordista, que assegurava a validade social dessas reivindicações, modificou consideravelmente as regras do jogo. Ainda que os critérios anteriores permaneçam válidos, uma vez que problemas de democracia, justiça ou vida boa permaneçam na ordem do dia, a instauração da ordem neoliberal engendrou uma série de novos problemas que não podem ser compreendidos apenas a partir de tais normas, donde há a necessidade da introdução do conceito de sofrimento social. Entre tais problemas, contam a emergência do sofrimento ligado à mobilização da subjetividade na nova organização do trabalho, o sofrimento vinculado à vulnerabilidade à dominação que caracteriza a desafiliação, o sofrimento produzido pela pobreza extrema e também a inibição da ação reivindicativa que resulta disso tudo (Renault, 2008, p. 396).

Baseando-se em trabalhos de psicologia do trabalho (sobretudo no de C. Dejours) e sociologia da dominação (S. Paugam, L. Boltanski, H. Kocyba, D. Linhardt, entre outros), Renault faz um impressionante diagnóstico acerca das transformações relacionadas ao pós-fordismo e da condição atual dos trabalhadores. De um modo geral, pode-se afirmar que a exploração e os lucros do pós-fordismo tendem a repousar menos no progresso técnico do que no aumento da quantidade de trabalho e na baixa do salário real - em termos marxistas. Tudo se passa como se houvesse um retorno à forma primitiva de extração da mais-valia (mais-valia absoluta) (Renault, 2008, p. 397). Dentre vários fenômenos, destacam-se a redução e a flexibilização das escalas organizacionais (por exemplo, modelo da empresa magra), exigência de auto-organização dos assalariados (trabalho em equipe e engajamento por projeto), a intensificação quantitativa (aceleração do ritmo de trabalho) e qualitativa (investimento subjetivo e imputação de responsabilidade) do trabalho e, às vezes, aumento da jornada de trabalho (sobretudo via abolição tendencial do limite simbólico da jornada de trabalho ou migração para países onde o direito trabalhista é menos rigoroso).

Quando a divisão do espaço da vida entre esfera do trabalho e esfera do não trabalho se dissolve gradualmente, isto é, quando o trabalhador é chamado a se engajar de "corpo e alma" em seu trabalho e a assumir as responsabilidades que acompanham a autonomia que lhe é acordada, as condições que reduziam, sobretudo nos países centrais, a experiência do trabalho a um assunto secundário não são mais cumpridas e a ideia de "fim da sociedade do trabalho" perde força. 
Nessas condições, a questão do sofrimento no trabalho se torna um problema público cujos aspectos políticos se tornam fundamentais (Renault, 2008, p. 398).

Nesse contexto, o sofrimento se explica pela conjunção de uma pressão subjetiva crescente (designada notadamente pela categoria popular de "stress") e de novas coerções físicas (crescimento de tarefas repetitivas, patologias ligadas à sobrecarga). $\mathrm{O}$ sofrimento resulta igualmente de normas contraditórias às quais os trabalhadores são submetidos. Como, por exemplo, assumir a responsabilidade ligada à autonomia em contextos nos quais não há margem de manobra, contribuir para o aumento de produtividade da empresa quando os efetivos diminuem ou ainda continuar a se engajar no trabalho como atividade cooperativa em um contexto de atomização dos coletivos de trabalho e de concorrência crescente entre os trabalhadores (Renault, 2008, p. 339). Enfim, trata-se de uma mudança na mobilização da subjetividade no trabalho. Se o fordismo procurou aumentar os ganhos mobilizando o corpo de modo eficaz, o pós-fordismo procura intensificar o trabalho mobilizando a autonomia e a responsabilidade dos trabalhadores e lutando contra os momentos ociosos. Do ponto de vista empírico, isto se verifica inclusive pela degradação dos indicadores da saúde no trabalho (licenças, acidentes de trabalho, consumo de psicotrópicos etc.).

Assim, o conceito de sofrimento social introduzido por Renault tem por função caracterizar algumas das experiências sociais negativas mais significativas de nossa época que não podem ser reduzidas a efeitos transitórios de transformações sociais em curso; antes, trata-se de se concentrar sobre as concepções relativas a uma etiologia sociais de desordens especificamente sociais e não necessariamente patológicas, bem como sobre o estudo de desordens subjetivas produzidas por estruturas sociais estabilizadas (Renault, 2008, p. 57).

\section{Sobre alguns limites da atual filosofia social e o desafio do capitalismo}

No entanto, como observou Haber, uma possível objeção que poderia ser levantada contra esse foco sobre as patologias vividas, concebidas como particularmente reveladoras do "social", é que ele tende a perceber a dimensão coletiva como um poder externo ameaçador mais do que como um ambiente ou uma realidade autônoma. Sobre esse ponto, Catherine Colliot-Thélène nos lembra que "faz parte de uma teoria crítica destacar o que são esses poderes, $a$ fortiori se eles não são imediatamente aparentes para aqueles que são afetados. Ao se focalizar sobre o vivido da dominação, pode-se esquecer de analisar suas causas" (Colliot-Thélène, 2015, p. 177). Certamente, uma filosofia social baseada em fatos patológicos e seus impactos subjetivos permanece compatível 
com uma abordagem forte do social, bem como com um diagnóstico das causas imediatas do sofrimento e das patologias, como evidenciado pelo trabalho de Renault sobre o pós-fordismo. No entanto, a filosofia social contemporânea tende, apesar de tudo, a descrever um social que poderia ser descrito como mais distante, mais ambíguo, mais inquietante. Sob a forma de instituições e dispositivos, o fenômeno social não aparece tanto como um conjunto de apoios positivos para os sujeitos, mas sobretudo como um conjunto de fatores de internalizações e de integrações deletérias, isto é, como o que domina e não como o que capacita o indivíduo. Falta talvez uma abordagem mais específica, mais aprofundada e direta dos mecanismos de dominação e das causas das experiências negativas. A partir dessa constatação, Haber desenvolveu uma tese que será muito importante para os nossos propósitos:

Por isso, é correto afirmar que levar mais a sério o indivíduo, como muito se fez recentemente em filosofia social, é arriscar começando por qualificar o social do exterior, levando a sério a sua alteridade. Nossa tese será que o risco de perda do social pode ser compensado, sem que seja esquecida a passagem revigorante pelo indivíduo, por meio de uma tomada de consideração da problemática do capitalismo (Haber, 2012, p. 145, grifo nosso).

Como compreender essa tese, se acabamos de notar que a filosofia social, especialmente a de matriz francesa, contribuiu bastante para a consideração de patologias sociais ligadas à dimensão do trabalho sob o neoliberalismo ou neocapitalismo? Na verdade, se seguirmos o raciocínio de Haber, a proposta de reinvestir o tema do capitalismo significa aqui se referir de forma mais global e mais direta ou mais "objetiva" a esse fenômeno, de modo que a filosofia social poderia vislumbrar a "superação" de seu momento "individualista" a fim de recuperar positivamente o sentido da efetividade social e histórica. Segundo esse ponto de vista, boa parte da filosofia social contemporânea deixaria na sombra notadamente a questão de saber em que consiste exatamente o próprio do capitalismo como fenômeno sócio-histórico e enquanto lógica social, que aparece na modernidade como uma das principais causas de patologias sociais e de experiências negativas. Tratar-se-ia então de analisar não só a perspectiva dos dominados, mas também a perspectiva dos dominantes, a fim de melhor se compreender os mecanismos de dominação e os poderes implicados na produção de tais patologias. De acordo com Haber, há muitas maneiras de se engajar nessa via, como aquela que concerne à interpretação da atual fase histórica do capitalismo, ou ainda a explicitação e radicalização do significado político do discurso da filosofia social, em relação com os problemas gerados pela expansão capitalista. No entanto, um caminho privilegiado parece ser a possibilidade de uma reorientação em torno de assuntos mais diretamente 
relacionados à ontologia social, o qual reúne pesquisas que giram em torno das seguintes questões: quanta autonomia devemos conceder às realidades coletivas? Em que medida, elas podem ser reduzidas a um nível distinto, por exemplo, a ação individual, e se elas não podem, por quê? É, nesse campo, na verdade, que são justificados o uso e o questionamento dessas grandes categorias que nos servem normalmente para desenvolver o sentido do coletivo em geral: o social é, basicamente, composto de estruturas, de convenções, de sistemas, de interações, de instituições, de dominações, de efeitos laterais de ações anteriores ou presentes? Ele é principalmente o produto da atividade humana ou um dos seus pressupostos logicamente anteriores (Haber, 2012, p. 132)?3

Do ponto de vista desse campo de questões, podemos destacar o fato de que as visões deterministas e funcionalistas da sociedade, que sempre foram influentes, se recompõem hoje em torno de uma certa interpretação "absolutista" do capitalismo, que se tornou novamente um grande polo de atração da discussão. De acordo com essa visão, o capitalismo deveria ser compreendido principalmente como uma espécie de grande máquina ou de processo totalitário que englobaria completamente do mundo contemporâneo, incluindo o mais íntimo das subjetividades (Vioulac, 2009; 2013; Jappe, 2003; Kurz, 2011). Nesse contexto, categorias tais como valor, fetichismo e capital designam os verdadeiros agentes sociais, na forma de macrossujeitos; os humanos, tanto os dominantes quanto os dominados, são meros portadores de relações sociais capitalistas e vítimas de suas formas de socialização. Apesar do interesse filosófico de abordar o sistema capitalista como uma totalidade, essa abordagem levanta uma série de dificuldades. Acima de tudo, há o problema inerente de uma abordagem que ignora a questão da ação e das subjetividades e de como estas internalizam e, eventualmente, reagem aos imperativos sistêmicos. Portanto, a análise torna-se demasiado "sistêmica" no sentido de que o capital reina sozinho, o valor se valoriza por si só, e não há mais conflitos sociais, resistências ou alternativas possíveis. Alguns desses teóricos estão trabalhando também com a ideia de uma crise sistêmica terminal do capitalismo, mas sem abordar a crise social e a luta, como se o sistema entrasse em colapso "automaticamente". ${ }^{4}$

3 Para mais detalhes sobre ontologia social, ver Searle (1997) e Livet e Nef (2009).

4 Por exemplo, Jappe escreve: "Por que estamos tão seguros de que o próprio capitalismo escapa ao ciclo de nascimento, crescimento e morte? Ele não poderia conter limites intrínsecos ao seu desenvolvimento, limites que não residem apenas na existência de um inimigo declarado (o proletariado, os povos oprimidos), nem apenas no esgotamento dos recursos naturais? Durante a crise, esteve novamente na moda citar Marx. Mas o pensador alemão não só falou de luta de classes. Ele também previu a possibilidade de que um dia a máquina capitalista parasse sozinha, de que sua dinâmica se esgotasse" (Jappe, 2009, p. 5). 
Falta-lhe precisamente o ponto forte da filosofia social, ou seja, levar a sério as experiências sociais vividas. ${ }^{5}$

Por outro lado, essa análise "absolutista" por demais abstrata e totalizante padece de uma interpretação mais concreta, dinâmica e historicamente situada do capitalismo. Sobre esse ponto, uma maior abertura para a sociologia e a economia política poderia ser muito bem-sucedida. De uma forma menos apressada e mais concreta e histórica, as teorias do sistema-mundo (a partir de Wallerstein e Braudel) talvez permitam ao filósofo constituir um terreno mais adequado no qual possa se colocar questões ontológicas relacionadas com a interpretação do capitalismo. Por exemplo, em que medida o capitalismo constitui um sistema? Até que ponto, ele é impulsionado por leis? Para esses autores, historicamente, o capitalismo se apresenta sempre como um todo geograficamente polarizado e hierárquico, e não apenas como um modo de produção. Ele pode, então, ser entendido como um sistema, não no sentido de um dispositivo mecânico e abstrato existindo por si mesmo, mas como algo construído sobre a base das relações socioespaciais relativamente estáveis (Arrighi, 2010; Braudel, 1993; 2014; Wallerstein, 2004). Em discussões com essa literatura, um filósofo como Jacques Bidet (2011) avança por exemplo a tese de que o "sistema" e seu dinamismo tem eficácia apenas por intermédio de uma estrutura, ou seja, por meio de conjuntos sociológicos mediadores (as classes, os Estados). Seja como for, Haber conclui assim que a passagem pela ontologia social e pela abordagem do capitalismo como um fenômeno social global e merecedor de uma análise holista, ainda que não necessariamente "sistêmica", é algo necessário para a renovação e para o avanço da filosofia social:

É suficiente concluir que, se não quiser se fechar em uma abordagem puramente escolástica, a "ontologia social" não pode deixar de enfrentar os problemas fascinantes que nos obrigam a retomar as concepções do capitalismo mais favoráveis às perspectivas holistas (o capitalismo como um sistema e processo global), forçando-nos, assim, a reencontrar o sentido do peso da realidade que pertence à objetividade social. Uma objetividade social que, se ela comporta de fato esta dimensão, também é sempre algo mais do que uma causa de alienação para os indivíduos, outra coisa que não seja apenas um poder transcendente e irracional. (Haber, 2012, pp. 146-147, grifo nosso)

5 Sobre esse ponto, deve-se notar que, desde o início, Honneth privilegiava a dimensão interativa e pragmática dos atores sociais enquanto ponto de vista básico da teoria social. Ao contrário de Habermas e das abordagens sistêmicas em geral, Honneth procura então mostrar que o desenvolvimento do sistema capitalista e da burocracia estatal é mediada por normas sociais e depende dos conflitos que moldaram as instituições e as práticas sociais em geral. Não há nenhum sistema autônomo, independente dos agentes (Cf. Honneth, 1986, p. 289). Para uma discussão detalhada acerca da fecundidade de uma abordagem da economia compatível com a perspectiva honnethiana, ver Deranty (2010). 
No entanto, podemos nos perguntar: será que não há outra maneira de alcançar a problemática da objetividade social capitalista sem abdicar de algumas realizações da filosofia social contemporânea? No que se segue, vamos esboçar, brevemente e de modo ainda introdutório, o caminho que acreditamos ser o mais produtivo para a filosofia social na sua tentativa de abordar o fenômeno capitalista.

\section{Filosofia social e capitalismo: por uma abordagem "fenomenológica" e normativa}

Como o próprio Haber reconhece, a filosofia social, em função do projeto que a anima, deve buscar se reconhecer em determinadas orientações das Ciências Sociais. Essas se mostram consumidoras e sobretudo produtoras de modelos interpretativos em teoria social que possuem todas as qualidades necessárias para serem classificados como filosóficos. Ora, hoje há uma tendência de "dessubstancialização" do social dentro de algumas orientações sociológicas que parecem questionar a perspectiva ontológica que privilegia exclusivamente a abordagem objetivista da realidade social. Não caberia então à filosofia social se apropriar, à sua maneira, dessa tendência? Como aponta Haber, "a prevalência desses temas parece mostrar que os gestos sociológicos primordiais, aqueles que definem os interesses de conhecimento capazes de abrir o campo de conhecimento da realidade social em sua totalidade, não podem mais permanecer na sombra da objetividade social" (2012, p. 135). Ele se refere nessa passagem às abordagens sociológicas que reivindicam o pragmatismo e a fenomenologia.

Com efeito, a fenomenologia, a sociologia compreensiva, o interacionismo, cada um em seu próprio estilo, contribuíram, ao longo da história da teoria social para desafiar o modelo da objetividade social como resultado congelado de ações passadas. Falta a este último precisamente o momento em que o social é efetivamente estruturado, o momento em que a sociedade se estabiliza, onde há participação e engajamento entre os atores envolvidos. Quando parte da sociologia de hoje reivindica o "pragmatismo", reavivando em certo sentido esse movimento histórico que surge com os movimentos mencionados acima, é para fazer valer o ponto de vista do ator e do coletivo que, confrontados com problemas e conflitos, improvisam soluções, com base, é verdade, em modelos de resolução disponíveis, mas também explorando criativamente as margens de indeterminação oferecidas pelas situações. ${ }^{6}$ 
Como observado por Andreas Reckwitz, desde a década de 1970, vários autores se dedicaram à construção de uma abordagem praxeológica: Pierre Bourdieu, mas também Anthony Giddens, Garfinkel, Latour, Charles Taylor etc. O que há de comum entre esses teóricos? Ao tentar uma síntese, Reckwitz define as práticas sociais da seguinte maneira:

Uma "prática" (Praktik) é um tipo de comportamento rotineiro composta de vários
elementos, interligados entre si: formas de atividades corporais, formas de atividades
mentais, "coisas" e seu uso, um conhecimento de fundo na forma de compreensão,
know-how, estados de emoção e conhecimento motivacional. Uma prática - uma
maneira de cozinhar, consumir, trabalhar, investigar, cuidar de si mesmo ou de outros,
etc. - forma, por assim dizer, um "bloco" cuja existência depende necessariamente
da existência e da interconectividade específica desses elementos, e que não pode ser
reduzido a nenhum desses elementos (Reckwitz, 2002, p. 250).

Se é assim, não poderíamos vislumbrar uma análise "positiva" do capitalismo - isto é, uma análise que considera o capitalismo como um fenômeno social que possui consistência própria e constitui sempre algo mais do que uma causa de alienação para os indivíduos - que não seja "objetivista"? Em outras palavras, uma filosofia social alimentada de discussões sociológicas menos objetivistas não seria capaz de trazer algo mais do que uma análise holística do capitalismo (o capitalismo como um sistema e processo global)? Em relação a essa tendência de dessubstancialização do social, a filosofia social não deveria justamente procurar entender como o social capitalista "se faz" por meio das ações e práticas sociais dos agentes ou atores capitalistas? O capitalismo pode prescindir da "cumplicidade" dos seus agentes? Por que se limitar a uma ontologia social que só discute a natureza sistêmica do capitalismo, o peso da realidade estável, em suma, o social como "fato consumado" típico das abordagens objetivistas?

Em nossa opinião, a principal limitação da filosofia social contemporânea não é a falta de uma abordagem objetivista do social, mas antes o lugar secundário reservado ao esforço de compreensão da especificidade da lógica por trás da prática capitalista, ou seja, das ações que contribuem para a criação e para a reprodução da realidade capitalista. A filosofia social se encontra, portanto, em uma situação semelhante à da sociologia do trabalho, se seguirmos aqui Marie-Anne Dujarier, para quem é preciso tentar ir além do que ela chama de "sociologia da recepção" das prescrições e dos dispositivos organizacionais e de gestão. Ela enfatiza o fato de que a descrição e a análise sociológica do trabalho de direção e produção de prescrições permanecem raras nesse campo (Dujarier, 2012, p. viii). Por que se limitar às experiências negativas e à recepção daquilo que é produzido pelas atividades capitalistas? Por que não se interessar pelo ponto de vista que caracteriza aqueles que se empenham na reprodução social 
capitalista? Se queremos manter as conquistas analíticas da filosofia social, vemos com isso que falta a essa última não tanto uma análise sistêmica ou estruturalista do capitalismo, mas sim o que talvez possamos chamar de uma teoria das práticas sociais capitalistas.

Se aceitarmos essa hipótese, como uma abordagem filosófica do social poderia contribuir para essa problemática? Que sentido pode ter aqui uma abordagem praxeológica do capitalismo? Acreditamos que a resposta a essa pergunta pode envolver pelo menos dois aspectos. Em primeiro lugar, essa abordagem implica sobretudo uma tentativa de problematizar algo que normalmente é recebido de forma acrítica e "natural". Trata-se de mostrar que uma coisa que é tomada como simplesmente existente corresponde a um ponto de vista particular, fundado por uma sociabilidade específica. Isso quer dizer que uma teoria das práticas capitalistas recebe aqui imediatamente uma função crítica, envolvendo uma análise das condições de possibilidade de uma visão ou de uma perspectiva de mundo específica, evidenciando o caráter histórico, contingente e socialmente determinado de seus pressupostos. Em outras palavras, o que se acredita ver como absolutamente existente (por exemplo, o valor de uma mercadoria) nada mais é que um fenômeno, um ponto de vista que é válido sob certas condições, para certos indivíduos e certos papéis e práticas sociais.

Dentro do contexto de uma eventual renovação da filosofia social, essa teria, assim, a tarefa de desmistificar e de revelar os pressupostos específicos do ponto de vista ou da perspectiva dos indivíduos que se envolvem em práticas que poderiam ser caracterizadas como capitalistas. Com isso, vemos que ela não pode se contentar com uma abordagem do social que descreveria a realidade fundamental da objetividade social do ponto de vista de um observador externo. Portanto, não é suficiente dizer que a dinâmica capitalista constitui um sistema, ou pressupõe uma estrutura; ou então que o capitalismo é melhor entendido a partir de uma ontologia processual ou segundo o ponto de vista da totalidade. Tudo isso pode ser verdade, mas enquanto permanecermos em uma posição de "sobrevoo", não avançaremos sobre a questão daquilo que "faz" ou produz tal realidade e tal dinâmica. A filosofia social deve abordar o social em processo de constituição e, para isso, deve adotar uma perspectiva mais interna ou compreensiva em relação às práticas que contribuem para a reprodução desse social. De fato, se o capital não pode realmente funcionar sozinho, se o capitalismo precisa de capitalistas, então estes devem assumir, explícita ou implicitamente, consciente ou inconscientemente, um ponto de vista particular, ou melhor, certas normas, que tornam suas práticas inteligíveis. 
Christian Lotz adota uma posição semelhante a essa em sua investigação, a partir de Marx e Kant, sobre o que ele chama de "esquema capitalista". Vejamos como ele a explica:

Em suma, uma coisa sob o esquema capitalista e em um mundo capitalista é algo que já aparece em uma determinada forma social antes que possamos nos referir a ela de alguma forma abstratamente cognitiva ou epistemológica (se tal coisa for possível). Por exemplo, quando Marx começa $O$ Capital com a observação de que a riqueza nas sociedades capitalistas “aparece como uma imensa coleção de mercadorias", ele aponta para o problema que tenho em mente. Por um lado, "coisas" não são simplesmente "objetos" nus sob o capitalismo; em vez disso, eles são encontrados como um tipo particular de coisa, neste caso, como mercadorias. Por "mercadorias", como veremos mais adiante, não queremos simplesmente dizer sopas e caixas de pizza; em vez disso, as mercadorias são elas mesmas a expressão de relações sociais, e, assim, em princípio, tudo pode se tornar uma mercadoria sob o capitalismo. Por conseguinte, as mercadorias não são objetos fixados ontologicamente, como árvores ou obras de arte (que podem tornar-se mercadorias); em vez disso, o que queremos dizer quando nos referimos a mercadorias é uma forma. No entanto, a forma sob a qual essas coisas aparecem como mercadorias permanece escondida e precisa de exposição (seja através de uma Crítica da Economia Política ou de uma fenomenologia) para mostrar que a coisa não é um objeto de percepção, mas é esquematizada como uma relação social (na forma de dinheiro, valor, capital, etc.). Então, novamente, encontrar "objetos" no capitalismo significa encontrá-los de forma esquemática, ou seja, como mercadorias [...] Consequentemente, o que realmente encontramos através do esquema é a forma social através da qual as entidades se tornam acessíveis para nós (Lotz, 2014, p. 40, grifo nosso).

O que Lotz está explicando neste trecho é precisamente o fato de que as relações sociais capitalistas impõem um ponto de vista, um "esquema" específico, por intermédio do qual a realidade se mostra ou se "revela" para nós, de modo que as entidades existentes se tornam acessíveis. É por isso que não podemos tomar uma mercadoria como se fosse uma entidade ontologicamente existente de maneira absoluta. Da mesma forma, atrás do ponto de vista de alguém que persegue a acumulação de capital, escondem-se muitos pressupostos socialmente determinados. Assim, vemos que, nesse contexto, a crítica da economia política se junta à perspectiva e à tarefa do que ele chama de fenomenologia social materialista, isto é, de uma fenomenologia que renuncia ao sujeito transcendental e se concentra nas condições sócio-históricas de sua produção. Entre os elementos de tal esclarecimento fenomenológico, poderíamos, por exemplo, vislumbrar as categorias de espacialidade, de temporalidade, de substância e de relação. A cada uma dessas categorias, corresponderia uma particularidade que constitui um ponto de vista capaz de atribuir uma forma específica para as entidades existentes. 
De modo similar, Rahel Jaeggi (2015) preconiza uma abordagem praxeológica da economia. Jaeggi considera o campo da economia como estando, em poucas palavras, preocupado com a satisfação das necessidades reprodutivas da sociedade pela produção e distribuição de bens e serviços. É fácil perceber, então, que cada elemento que entra em jogo aqui - por exemplo, propriedade, intercâmbio de mercado e trabalho - pode ser visto como uma configuração de práticas e instituições sociais. Jaeggi argumenta que, desse ponto de vista, as práticas relacionadas a questões econômicas estão inter-relacionadas ou mesmo interligadas com outras práticas e interpretações não econômicas. Eles fazem parte do que ela chamou de "conjunto" (ensemble) de práticas sociais. Assim, tomando o exemplo da propriedade, ela observa que diferentes interpretações do título legal de "propriedade" são acompanhadas por diferentes práticas de aquisição, conservação e disposição do que é entendido como propriedade em uma ordem social. Podemos alienar mais ou menos sem limites, ou não; uma pessoa apropria-se de maneiras diferentes e certos modos de apropriação valem como criação de propriedade, outros não. Ou seja, o que é percebido pelos atores como sendo uma propriedade, ou ainda o que é reconhecido socialmente como trabalho e como mercadoria, tem pressupostos que não são simplesmente "naturais" ou trans-históricos, mas que variam conforme o tipo de estrutura social e econômica que lhe corresponde. Esses são apenas alguns breves exemplos de como essa abordagem das práticas sociais pode ajudar a filosofia social a dar conta do "social capitalista" de modo ao mesmo tempo "positivo" ou objetivo sem cair num objetivismo ou sistemismo que colocaria em segundo plano a dimensão dos atores sociais.

O segundo aspecto de uma possível contribuição filosófica à análise "positiva" do social capitalista reside em uma conquista central da filosofia social contemporânea. Trata-se de levar a sério a dimensão normativa imanente ao social. Vimos que, de acordo com Fischbach, a Filosofia, na sua concepção do social, o considera de forma preponderante sob o ângulo de sua normatividade. O ideal expresso nas instituições e nas práticas sociais é assim integrado e faz parte, tanto quanto o "real" ou o estrutural, do social em questão. Para retomar a proposta de Fischbach, "por social ou sociedade, não se entende somente algo que é, somente algo do qual se constata a existência, mas algo de almejado e de desejável, algo a se querer e a se fazer; não apenas alguma coisa que vemos, mas que queremos; não apenas algo a que nos submetemos, mas algo que escolhemos" (Fischbach, 2013, p. 20). Ultrapassa-se assim uma interpretação somente descritiva e objetivista do social fundada em algum tipo de "ontologia da presença". Assumindo a perspectiva interna dos participantes das práticas e papéis sociais, constata-se igualmente o peso da realidade dessa normatividade, 
dessa transcendência imanente que não se limita ao que existe atualmente. E levando a sério a normatividade, compreende-se melhor o que se encontra fora do âmbito de uma perspectiva externa do observador: a especificidade normativa da lógica por trás das ações que constituem o social.

No entanto, se o que está em jogo é a compreensão da lógica do capital, precisamos discernir uma "normatividade amoral". De fato, se a filosofia social teve até agora a tendência de compreender a normatividade imanente ao social de um ponto de vista exclusivamente moral, segundo aquilo que diz respeito à boa vida e o justo, é preciso doravante saber analisar normas neutras sobre esse ponto. Como lembram Boltanski e Chiapello, "o capitalismo é, com efeito, sem dúvida, a única, ou pelo menos a principal, forma histórica ordenadora de práticas coletivas a ser perfeitamente separada da esfera moral, no sentido de que ele encontra a sua finalidade em si mesmo (a acumulação de capital como um objetivo em si) e não por referência, não só a um bem comum, mas mesmo aos interesses de um ser coletivo como o povo, o Estado, classe social" (Boltanski; Chiapello, 2011, pp. 59-60). Isso certamente não significa que a moralidade se torna insignificante, mas apenas que uma das especificidades da normatividade capitalista é a sua indiferença para com os motivos concretos e morais de engajamento. É óbvio que o capitalismo deve encontrar alguns motivos morais de adesão, mas esse é um outro problema. O ponto aqui é enfatizar a necessidade de compreender a normatividade capitalista de uma forma não imediatamente moral, pois se o que se quer acima de tudo no capitalismo é a acumulação infinita, então é preciso dar conta da especificidade dessa norma como tal, sem levar imediatamente em conta motivos morais. Isto é, nessa abordagem normativa do capitalismo, não se trata apenas de analisar suas estruturas sociais atuais, o modo de produção contemporâneo, mas a norma imanente às práticas dos agentes capitalistas (proprietários, managers etc.) a fim de dar conta não apenas da especificidade ou da natureza dessa norma (por exemplo, em que consiste ter como norma uma acumulação sem limites de riqueza abstrata?), mas também das tendências inerentes a essa forma de organização social.

Em resumo, a filosofia social pode e deve investir em uma análise direta e positiva do que está por trás e do que constitui em grande parte a causa das experiências negativas nas sociedades modernas, a saber o fenômeno capitalista. Como Colliot-Thélène lembra:

Para voltar a Marx, é verdade que ele considerava que o ponto de vista crítico sobre a realidade social devia ser enraizado nessa própria realidade, e que ele ligava por esta razão a possibilidade de uma crítica da economia política à existência, no próprio seio da sociedade capitalista, de uma classe cuja existência própria chamava à subversão 
desta sociedade. Mas a crítica da economia política supunha também um trabalho propriamente teórico, aquele ao qual ele dedicou anos de trabalho e aos quais devemos $O$ Capital. Na medida em que Marx pode ser citado como um exemplo do que deve ser e fazer um teórico "crítico", este não pode ter por única tarefa a de ser o porta-voz dos dominados e subalternos. É-lhe também preciso mobilizar suas competências teóricas para atualizar as lógicas estruturais globais que determinam as desigualdades da distribuição das riquezas, dos poderes e do reconhecimento social (Colliot-Thélène, 2015, p. 176, grifo nosso). ${ }^{7}$

Naturalmente, essa proposta de inflexão na prática da filosofia social, que no fundo tenta retomar certos expedientes consagrados pela crítica da economia política de Marx, é complementar em relação ao modo como ela tem sido praticada até aqui, os dois modos não são de forma alguma mutuamente exclusivos. Pelo contrário, pois, desde Marx, a teoria crítica está convencida de que a sociedade não é compreensível fora da perspectiva de sua transformação prática.

Sendo assim acreditamos que a filosofia social pode contribuir para a inteligência da lógica do capital, oferecendo uma análise ao mesmo tempo "praxeológica" e "normativa" do social capitalista, adotando uma perspectiva compreensiva das práticas capitalistas. Obviamente, seria necessário especificar melhor em que consiste tal proposta e aprofundar os mecanismos de uma abordagem sócio-filosófica do capitalismo, o que não seria, entretanto, possível nos limites desse artigo, cujo principal objetivo foi o de apenas esboçar essa proposta de renovação a partir da colocação de um determinado problema no âmbito da filosofia social contemporânea. $\mathrm{O}$ aprofundamento dos pontos mencionados constitui, pois, tema para outro artigo. ${ }^{8}$

\section{Referências}

ARRIGHI, G. "The Long Twentieth Century: Money, Power and the Origins of Our Times". New edition. London; New York: Verso, 2010.

BIDET, J. “L’État-monde”. Paris: PUF, 2011.

7 Colliot-Thélène prefere classificar essa démarche como uma "filosofia política crítica", ou ainda como "uma teoria da política entendida como teoria dos poderes". No entanto, acreditamos que manter o nome de "filosofia social" é mais produtivo e preciso na medida em que o conceito de filosofia política ainda faz referência mais imediatamente a um campo limitado ao poder político (até mesmo estatal) em primeiro lugar, enquanto que propomos focalizar no poder e na lógica econômica capitalista, e sobre o capitalismo como forma histórica de organização social. A filosofia social parece possuir, nessa perspectiva, um caráter mais adequadamente abrangente naquilo que diz respeito ao objeto de estudo em questão.

8 Em nossa tese de doutorado (Da Hora Pereira, 2016), procuramos desenvolver melhor os pontos mencionados. Cf. especialmente a terceira parte da tese. 
BOLTANSKI, L., CHIAPELLO, E. (1999). "Le Nouvel Esprit Du Capitalisme”. Nova edição com novo posfácio. Paris: Gallimard, 2011.

BRAUDEL, F. (1985). “La Dynamique Du Capitalisme”. Paris: Flammarion, 2014. . "Civilisation, Économie Et Capitalisme, XVe-XVIIIe siècle, tome 3 : Le temps du monde". Paris: Le Livre de Poche, 1993.

COLLIOT-THÉLÈNE, C. “Pourquoi La Philosophie Sociale ?”, Actuel Marx, Nr. 58, pp. 172-189, 2015.

CORREAA, D. S. "Do problema do social ao social como problema: elementos para uma leitura da sociologia pragmática francesa". Revista de Ciências Sociais - Política \& Trabalho, Vol. 1, Nr. 40, 2014.

DA HORA PEREIRA, L. (2016). "Le capitalisme comme forme historique et comme pratique sociale. Une contribution à la philosophie sociale à partir de Marx et de la Théorie de la Régulation" (Tese de doutorado em filosofia). Universidade de ParisNanterre, Nanterre, França.

DEJOURS, C. (1998). "Souffrance En France : La Banalisation De L'injustice Sociale”. Paris: Points, 2014.

DERANTY, J.-P.R. "Critique Of Political Economy And Contemporary Critical Theory : A Defence Of Honneth's Theory Of Recognition”. In: ZURN, C. (ed.). The Philosophy of recognition: historical and contemporary perspectives. New York: Lexington Books, 2010.

DUJARIER, M.-A. “L'idéal Au Travail”. Paris: PUF, 2012.

FISCHBACH, F. "Comment penser philosophiquement le social ?". Cahiers Philosophiques, Nr. 132, pp. 7-20, 1 février 2013.

. "Manifeste pour une philosophie sociale". Paris: La Découverte, 2009a.

"Sans Objet. Capitalisme, Subjectivité, Aliénation". Paris: Vrin, 2009b.

HABER, S. "L'aliénation : Vie sociale et expérience de la dépossession". Paris: Presses Universitaires de France - PUF, 2007.

."Renouveau de la philosophie sociale ?". Esprit, Nr. 3, pp. 131-149, mars/ avril 2012.

HONNETH, A. (1992). "Kampf um Anerkennung. Zur moralischen Grammatik sozialer Konflikte". Mit einem neuen Nachwort. Frankfurt am Main: Suhrkamp, 2003.

. "Das Ich im Wir: Studien zur Anerkennungstheorie". Berlin: Suhrkamp, 2012. . "Das Recht der Freiheit: Grundriß einer demokratischen Sittlichkeit". Berlin:

Suhrkamp, 2013.

"Kritik der Macht". Frankfurt am Main: Suhrkamp, 1986.

.La Société Du Mépris". Traduzido por A. Dupeyrix, P. Rusch, O. Voirol.

Paris: La Découverte, 2008.

."Verdinglichung: Eine anerkennungstheoretische Studie". Frankfurt am Main:

Suhrkamp, 2005.

JAEGGI, R. "A Wide Concept of Economy: Economy as a Social Practice and the Critique of Capitalism". 2015. Disponível em https://www.academia.edu/20601920/ Economy_as_a_Social_Practice. (Acessado em 01/06/2017). 
. "Entfremdung". Frankfurt am Main: Campus, 2005.

JAPPE, A. “Crédit à mort". Revue Lignes, Nr. 30, 2009. Disponível em http://inventin. lautre.net/livres/Anselm-Jappe-Credit-a-mort.pdf. (Acessado em 01 de setembro de 2016).

. "Les Aventures De La marchandise : Pour Une Nouvelle Critique De La Valeur". Paris: Denoël, 2003.

KURZ, R. "Vies et mort du capitalisme : Chroniques de la crise". Traduzido por O. Galtier, W. Kukulies e L. Mercier. Paris: Nouvelles Editions Lignes, 2011.

LIVET, P., NEF, F. “Les êtres sociaux : Processus et virtualité". Paris: Editions Hermann, 2009.

LOTZ, C. "The Capitalist Schema: Time, Money, and the Culture of Abstraction". New York: Lexington Books, 2014.

RECKWITZ, A. "Toward a Theory of Social Practices A Development in Culturalist Theorizing". European Journal of Social Theory, Vol. 5, Nr. 2, 2002.

RENAULT, E. "Souffrances sociales". Paris: La Découverte, 2008. . "Théorie critique et critique immanente". In: VASSORT, P. Théorie critique de la crise. Illusio, Nr. 10/11. Caen: Le bord de l'eau, 2013.

SEARLE, J. R. "The Construction of Social Reality". New York: Free Press, 1997.

VIOULAC, J. "L'époque de la technique. Marx, Heidegger et l'accomplissement de la métaphysique". Paris: Presses Universitaires de France - PUF, 2009.

. "La logique totalitaire. Essai sur la crise de l'Occident". Paris: PUF, 2013.

WALLERSTEIN, I. M. "World-systems Analysis: An Introduction". Duke: Duke University Press, 2004. 